\title{
Consultoria internacional em expansão e formas emergentes de globalização das trocas e contenciosos gerenciais
}

Julio César Donadone

Introdução temática

Ao divisarmos o mundo organizacional nas últimas duas décadas, deparamonos com um conjunto de organizações que aparecem em posição de destaque. As empresas de consultoria organizacional despontam como um dos setores mais dinâmicos do período. Com presença constante na mídia, seus membros ocupam, com frequência, lugar em evidência nas principais revistas econômicas e gerenciais. Além disso, estão sediadas nas mais importantes cidades do mundo, comumente se destacando pela imponência de suas construçôes e de sua localização. As consultorias apresentam um faturamento e uma expansão que chamam a atenção, com crescimento das empresas líderes a uma taxa média de $20 \%$ ao ano, que as coloca entre os setores econômicos mais rentáveis do período e suplanta os índices anuais de desenvolvimento das principais economias. Em 1995, estima-se que o mercado mundial de consultorias em gestão organizacional alcançou a cifra de 40 bilhōes de dólares, valor que, em 2000, já superava os 100 bilhōes (ver Gráficos 1 e 2 no final deste artigo). 
O mercado de consultoria internacional

\section{Origens}

Para entender o processo de formação das empresas de consultoria que se destacam no cenário atual é necessário retornar ao final do século XIX e início do século XX. Nesse período, entre as décadas de 1850 e 1920, surgem as firmas que, posteriormente, por meio de fusões e aquisições iriam consolidar-se como os polos dominantes do espaço de consultoria mundial.

Dois países destacam-se como locais de origem das empresas de consultoria: a Inglaterra e os Estados Unidos. Este último configurando-se como principal espaço de construção das características que se tornariam elementos estruturantes das corporaçóes líderes do setor. Segundo pesquisa da Revista Consultants News de 2000, entre as dez maiores empresas do setor, seis têm origem norte-americana, duas têm sua origem na fusão de firmas inglesas e norte-americanas, uma tem origem inglesa e somente a francesa Gemini Consulting não é originária desses países. Como referência cronológica podemos citar a fundação, nos Estados Unidos, em 1886, da Arthur D. Little; em 1906, a Ernst \& Ernst e Arthur Young \& Company; em 1914, a Booz Hallen \& Hamilton; Arthur Andersen, em 1913; Mckinsey, em 1926; e, na Inglaterra, em 1849, tem-se a fundação da Price - segundo Coget (1999), a Price que, posteriormente, em 1865 tornar-se-ia a Pricewaterhouse, aparece como a mais antiga empresa de consultoria - e, em 1854, da Coopers. Entre as empresas citadas e que surgiram neste período, encontram-se oito das dez maiores empresas de consultoria do mercado mundial.

A primeira fase do desenvolvimento das consultorias está relacionada com o aumento do tamanho e da complexidade das organizações industriais nos Estados Unidos na passagem do século. Tal acontecimento trazia consigo inúmeras possibilidades para a atuação de engenheiros, advogados e contadores, como agentes externos detentores de um conhecimento específico, no auxílio da resolução dos problemas originários do processo de expansão das empresas.

Como formulado por Mckenna (1995) no período, as empresas em fase de expansão, que buscavam auxílio técnico, poderiam encontrá-lo em consultores como o engenheiro químico Arthur D. Little bem como em firmas de contabilidade como Arthur Andersen e Ernst \& Ernst que, na primeira década do século, já atuava em todo o território norte-americano e em subsidiárias de firmas de contabilidade inglesas, como a Price Waterhouse, as 
quais providenciavam auditoria externa e controle financeiro para as empresas em crescimento - as leis que discorriam sobre corporações inglesas (The Companies Act de 1879 e The Bankruptcy Act de 1883) mudaram o papel dos contadores que passaram de "guarda livros" para auditores. Fato que nos Estados Unidos só ocorreu na primeira década do século XX (Wilkinson, 1995). Quanto às questões jurídicas, havia uma expansão de unidades regionais que, conjuntamente com as situadas em Nova York, atendiam as divisões de companhias distribuídas nos estados norte-americanos. Ou seja, as três profissões, engenharia, contabilidade e direito, apresentavam um forte crescimento em número e tamanho das empresas a partir de 1890, fornecendo conselhos corporativos a um mercado que se expandia rapidamente.

Nas questões jurídicas e de contabilidade e , o crescimento da demanda por auxílio técnico estava vinculado à ratificação da décima sexta emenda da constituição norte-americana, que discorria sobre a taxação dos lucros das empresas e que, em 1916, tornou-se lei. Antigos apontadores (guarda-livros) transformaram-se em contadores. Auditores que anteriormente eram utilizados para atestar a verdade dos balanços e das operações financeiras perante os acionistas, os proprietários e os credores ganham um novo papel, passando a orientar seus clientes sobre o funcionamento das leis referentes aos impostos, bem como sobre a forma de minimizar as despesas com os mesmos. Como resultado da aplicação das novas taxções nas empresas, obteve-se um crescente acúmulo de informaçóes sobre as questóes financeiras: produtividade de ativos, fontes de lucro, assim como natureza e causa de custos e despesas, o que proporcionou aos contadores um poder crescente para usufruir desses dados no gerenciamento empresarial (Wasburn, 1996, pp. 47-53). Tal fato possibilitou ganho de espaço para a categoria na luta pelas posições dominantes do nascente mercado de consultoria e teve influência marcante nas formas de constituição e atuação das empresas no decorrer do século. Voltarei à questão da relevância de contadores e auditores nas sociedades anglo-saxônicas e suas consequências para a configuração do formato das consultorias quando discutir a difusão delas em outros países, cujos ambientes institucionais configuram outras formas de atuação e relevância para estes profissionais, por exemplo, a França e o Brasil.

Outro aspecto constitutivo do período é a ligação entre as diversas empresas, sejam elas especializadas em uma das demandas peculiares a engenharia, direito ou contabilidade, seja, o que se tornou mais comum na década de 1920, nas combinações dessas habilidades mediante o management engineering com o setor financeiro. Muitas vezes essas empresas eram con- 
tratadas pelos bancos no sentido de orientar suas companhias clientes quanto a aspectos organizacionais e contábeis, bem como para utilizá-las com a função de salvaguardas externas para os interesses dos investidores.

Os bancos utilizavam serviços internos e externos de engenheiros, contadores e advogados no intuito de avaliar o desempenho, a organização e as possibilidades de sucesso no financiamento, na compra ou na fusão de empresas. Nos anos de 1920, a atuação da Arthur Andersen \& Company e suas investigações sobre produtos, mercados, organização e perspectivas futuras serviam de avaliação para os financiamentos de bancos de investimentos em Nova York e Chicago. Os bancos, por meio da contratação de uma variedade de serviços que incluíam orientação sobre gerenciamento, planejamento, controle da empresa, e que tinham como respaldo a reputação do próprio estabelecimento financeiro, desempenharam um papel que encontraria semelhança somente nas décadas seguintes com a formação das empresas de consultoria (Mckenna, 1995).

Entretanto, em 1933, o congresso norte-americano aprovou o GlassSteagall Banking Act, como uma tentativa de resposta às questôes relacionadas com a quebra da Bolsa de Valores de Nova York, em 1929. O ato dividia em categorias opostas os bancos de investimento e os que trabalhavam com depósito de correntistas, ou seja, bancos comerciais e de investimentos. Conjuntamente, foi criada pelo congresso a Securities and Exchange Commission (SEC) no intuito de regular os mercados financeiros e o funcionamento da alavancagem econômica das empresas.

A nova legislação viria a reconfigurar a atuação dos bancos e teve importantes consequências para o formato que as consultorias iram assumir a partir daquele momento. Os bancos comerciais não poderiam atuar mais em atividades como seguros, ramos imobiliários ou atividades de consultoria, sendo forçados pelas normas federais a contratar empresas externas quanto às questôes de análise de falência ou sobre perspectivas de determinada companhia. Quanto aos bancos de investimento, estes não eram proibidos de realizarem consultorias, mas, no entanto, não poderiam utilizar seus quadros internos de engenheiros, contadores, advogados ou a combinação destes, representados pelo management engineering, para validar seus empréstimos ou nas avaliações de empresas.

Perante o novo cenário, houve um rápido crescimento de auditores contábeis independentes, assim como na institucionalização das consultorias organizacionais. Se, nos anos de 1920, as consultorias independentes viviam à sombra de contadores e engenheiros e demais quadros internos aos estabe- 
lecimentos financeiros e companhias locais e eram responsáveis pelo emprego de tais profissionais geralmente na análise de problemas específicos do andamento da produção ou de aspectos contábeis restritos, nos anos de 1930 grandes corporações, que incluem Union Carbide, Johnson Wax e Sears, passaram a contratá-los para analisar problemas relativos à estratégia, às novas formas de estrutura organizacional è̀ performance financeira.

A depressão econômica seguinte à quebra da bolsa também trouxe outros elementos que influenciaram na caracterização dos novos arranjos institucionais e organizacionais das empresas de consultoria na década de 1930. Se, de um lado, ela restringia a possibilidade das empresas de contratarem novos estudos sobre aspectos organizacionais, de outro, possibilitava uma série de oportunidades às empresas que, como no caso especifico da Mckinsey, se dedicavam à venda de um modelo de avaliação financeira. Ao mesmo tempo, tal levantamento servia como diagnóstico dos problemas das empresas e indicativo das possíveis soluções, bem como, de forma mais acentuada, fornecia uma referência de credibilidade perante os possíveis credores do setor financeiro que viam nos survey's bank uma forma legítima de avaliação dos riscos envolvidos nas transações. Entre as décadas de 1930 e 1940, o número de empresas de consultoria cresceu a uma taxa de $15 \%$ ao ano, passando de cem empresas, em 1930, para quatrocentas, em 1940.

A Segunda Guerra Mundial aparece como outro importante elemento na constituição do mercado de consultorias. Durante o conflito, em virtude do esforço de guerra, o governo norte-americano contratou, em grande número, consultores para reordenar as formas de gerenciamento das áreas militares, racionalizar a produção civil e dar suporte para a crescente expansão da administração federal. Exemplo disso são os estudos da Booz Alan e Hamilton na reorganização do Exército e da Marinha (Hewes Jr., 1996).

A utilização de consultores pelo governo, durante os esforços de guerra, trouxe consigo a possibilidade da abertura do setor público à atuação das empresas de consultoria. A criação, pelo congresso norte-americano, da Hoover Comission representa de forma emblemática o inter-relacionamento entre os dois setores. Criada em 1947, a comissão tinha o objetivo de coordenar forças-tarefa que seriam responsáveis pela reorganização do setor público norte-americano. Ele havia crescido nas últimas duas décadas, passando de 500 mil para 2 milhóes de empregados; o número de unidades administradas passara de menos de 500 para 1.880; e as despesas, de 3,6 para 42 bilhōes de dólares (Hoover, 1996). O trabalho foi estruturado em forças-tarefa lideradas por doze diferentes executivos, que tinham como 
suporte o emprego de consultores externos. Cabia às empresas de consultoria formular e reestruturar o setor executivo do governo, passando por questôes que envolviam desde o gerenciamento do corpo diretivo da Casa Branca até novas estruturas organizacionais do correio norte-americano.

Assim, ao se divisar o período entre o surgimento das primeiras firmas até os anos de 1940, podem-se identificar dois processos inter-relacionados, que aparecem como características estruturais na formação do mercado de consultoria. O primeiro é o processo de legitimação dos consultores como alternativa possível na análise e na gestão das organizações privadas ou públicas. Impulsionados pelas mudanças nas legislações quanto aos impostos e à normalização das relações entre setor financeiro e empresas, os consultores percorreram um interessante caminho que surgia como auxilio externo para problemas específicos, e, depois, ganhava o status de alternativa legítima e referencial para a análise do desempenho das empresas. Vale lembrar que, perante a impossibilidade, imposta pela lei, de oferecer o serviço de análise das empresas, os bancos buscavam alternativas externas, mas, também, recomendavam esta forma às empresas, como a maneira de produzir análises que pudessem ser reconhecidas tanto pelo setor empresarial como pelo setor financeiro. Reconhecimento que, na década de 1940, era estendido ao setor público. Como indicado por Mckenna em estudo sobre a Commission Hoover, os consultores eram vistos como elos institucionais responsáveis pela transferência do conhecimento organizacional do setor privado para o setor público.

O segundo processo, intrinsecamente ligado à questão dos mecanismos de obtenção de legitimidade por parte dos consultores, diz respeito às transformações do espaço contábil, ocasionadas pelas mudanças nas leis referentes aos impostos e às formas de relacionamento entre o setor financeiro e empresarial. Tais transformações iriam levantar a questão da utilização de conhecimentos contábeis como elemento central do trabalho dos consultores do período. Assim, a análise da gestão financeira, seja no intuito de reduzir a carga tributária, seja de avaliar o desempenho econômico da empresa para alavancar empréstimos bancários ou medir a rentabilidade de investimentos, passou a orientar o formato e a maneira de atuar das principais empresas do período.

O perfil do espaço de consultoria que emerge no período refletia a importância da questão contábil. De um lado, havia as accounting firms, que tinham como principais características de atuação a auditoria contábil, a orientação sobre questôes jurídicas e sobre questôes ligadas à gestão das em- 
presas. Este arranjo organizacional serviu de matriz para o desenvolvimento, nas décadas seguintes, das principais empresas de consultoria atuantes no mercado mundial: Pricewaterhouse, Coopers \& Lybrand, Deloitte, Arthur Young, Ernst \& Ernst, Arthur Andersen, Touche e Peat Marwick. Como outro polo do mercado de consultoria, surgiram as empresas não relacionadas com a accounting firms, com especial destaque para Mckinsey e BoozAlllen \& Hamilton. Ainda que não estivesse dentro da categoria anterior a importância da questão contábil para sua estruturação, cabe ressaltar, como exemplo mais emblemático, a trajetória da Mckinsey, que foi fortemente influenciada por sua atuação na elaboração de análises de saúde financeira empresarial, oriundas dos relatórios encomendados por instituições financeiras, os denominados survey's bank. $\mathrm{O}$ desenvolvimento cronológico da Booz-Allen também fornece elementos que corroboram a tese das similaridades de origem entre as accounting firms e as consultorias em estratégia. Em 1915, Ed Booz organiza um a joint venture, Business Research \& Development Company; com o objetivo de investigar as condiçôes de mercado em diferentes ramos; em 1919, ele funda Edwin G. Booz, Business Engineering Service, e o State Bank \& Trust of Evanston, IL, providenciou o empréstimo para o negócio e se tornou o seu primeiro cliente; uma estruturação que, ao lado das mudanças na legislação, se converteu em fator determinante para a constituição e o crescimento da empresa.

A questão da separação entre as consultorias originárias de accounting firms e as especializadas em estratégias abriu um espaço de diferenciação dentro do mercado de consultoria que, nas décadas seguintes, se tornaram polos antagônicos no âmbito dominante internacional, direcionando as possibilidades e as formas de atuação entre os consultores.

Nas décadas subsequentes à guerra, a difusão das consultorias, primeiramente, associa-se ao esforço norte-americano de reconstrução da Europa. A introdução de práticas gerenciais compunha um dos elementos da ajuda norte-americana e abria novas áreas de atuação dos consultores. A Arthur D. Little, por exemplo, abriu representaçóes em Paris, onde o escritório central de coordenação do plano Marshall estava localizado. A partir dos anos de 1960, o uso das consultorias ganha impulso com a penetração crescente de multinacionais norte-americanas - de maneira análoga, a crescente presença das multinacionais teve importante papel para a introdução das empresas líderes do setor de consultoria no Brasil a partir do final dos anos de 1950 (por exemplo, a chegada da Arthur Andersen em 1957). Arthur D. Little, Booz-Allen e Mckinsey abrem representações na 
Europa, e suas atuações concentram-se em aspectos organizacionais, especialmente com a difusão das formas de gestão e ordenação relativas à implementação da estrutura muldivisional, mais popularmente denominada "formatos M".

A trajetória da Mckinsey parece servir de referência para o entendimento da difusão e do crescimento do setor na Europa. No final dos anos de 1950, a firma instala-se na Inglaterra. A escolha deve-se à forte ligação entre as companhias norte-americanas e inglesas, referente à origem das empresas e a semelhanças da legislação sobre a contabilidade dos dois países; e à difusão de multinacionais norte-americanas na Inglaterra. Durante os anos de 1960, das cem maiores empresas inglesas, 32 haviam usado consultores com o intuito de realizar mudanças na sua organização, sendo a Mckinsey responsável por 22, dentre elas, empresas de grande representatividade como a ICI e a Dunlop. A Inglaterra serviu de cabeça de ponte para a atuação da empresa nos outros países europeus: a Mckinsey, por exemplo, iniciou suas atividades na Alemanha, na cidade de Dusselfolg, em 1964, e, na França, com a abertura de escritório de Paris, em 1965 (Kipping, 1996).

\section{A configuração das últimas décadas}

Os anos de 1980 marcam o início de significativas transformaçóes no mercado de consultoria organizacional. $\mathrm{O}$ crescimento e o destaque do setor, associados a mudanças nas formas de atuação, de relacionamento com as empresas contratantes e inserção nos mercados de divulgação e venda de pacotes gerenciais formataram características que serviram de suporte para a configuração e a importância que a área adquiriria nos anos de 1990 .

No período destacava-se a implementação de ferramentas gerenciais inspiradas nas ideias de gestão empresarial japonesa. Tais ferramentas, respaldadas pela divulgação do sucesso das indústrias japonesas, em especial no que diz respeito à conquista de consideráveis parcelas do mercado norteamericano de automóveis, apareciam como referência para as empresas.

As tentativas de recontextualização das práticas japonesas ofereceram um fértil terreno para a expansão das consultorias. Abriam-se novas frentes de atuação. Num primeiro momento, com as tentativas de interpretação e introdução de elementos das práticas gerenciais japonesas nas empresas ocidentais, sendo emblemática a discussão e a implantação dos Círculos de Controle de Qualidade (CCQs). Outro destaque do período e que fornecia novos campos de atuação foi o crescente mercado de certi- 
ficação sobre procedimentos de gestão e de processo produtivos, representados principalmente pelas normas ISO e, posteriormente, nos anos seguintes, por suas versões específicas, como a QS do setor automobilístico norte-americano.

No decorrer da década, os espaços de atuação das consultorias ganham novas dimensões, mudando o enfoque de características funcionais das práticas japonesas para pacotes gerenciais que visavam contemplar os diversos setores presentes nas empresas. Tal passagem evidencia-se na semântica e na abrangência das propostas que passam a enfocar "Filosofias da Qualidade", como o Kaizen, e, principalmente, pelos conteúdos atribuídos ao Total Quality Management (TQM).

Como observado por Cole (1998) em seus estudos sobre a constituição e a dinâmica dos movimentos pela Qualidade nas empresas norte-americanas, os consultores aparecem como os principais vetores de difusão e implantação das novas formas de gestão com inspiração japonesa. Segundo o autor, no decorrer dos anos de 1980 ocorre um processo de institucionalização de diversos agentes e instâncias profissionais e governamentais, que buscam formular os conteúdos atribuídos ao tema qualidade e também um acirramento na disputa pela divulgação e implantação relativas ao assunto. Tal formulação tem importância neste estudo por fornecer tanto indicações para os motivos do crescimento da utilização de consultores, como das estratégias de conquista de espaço de atuação das empresas de consultorias nos anos de 1990.

Outro componente que forneceu contribuições para o cenário no qual as consultorias passaram a atuar a partir dos anos de 1980 é a questão da Tecnologia de Informação (IT). Num primeiro momento, com as mudanças ocasionadas pela difusão dos computadores pessoais nas empresas e, posteriormente, com a introdução de "pacotes de gerenciamento" baseados na Tecnologia de Informação.

O incremento na informatização de aspectos administrativos e da produção com o intuito de ganhos de produtividade e utilização de softwares voltados à gestão de aspectos organizacionais, como, por exemplo, o MRP, abriu um importante mercado para as consultorias, e também serviu de base para transformaçôes na segmentação e nas formas de atuação do polo central das consultorias internacionais na década seguinte. Por exemplo, no suporte à introdução das questôes relacionadas com o uso da internet como ferramenta empresarial e na atuação de empresas especializadas em softwares de gestão como a SAP e a Oracle. 
Outro componente central para o entendimento das configurações e da constituição do setor de consultorias atual foi a criação da Andersen Consulting, empresa criada em 1989 a partir de um processo de divisão de negócios da Arthur Andersen Co. Ela nasce como a maior empresa de consultoria do mundo, contanto com um contingente de 21.400 empregados e receita de 1,6 bilhões de dólares no seu primeiro ano.

Sua criação trouxe uma série de características assumidas pelo mercado de consultoria anos de 1990. Um elemento inicial a se destacar são as novas formas de composição entre consultores e auditores, os primeiros passando de uma condição de inseridos em grandes empresas de auditoria e contabilidade para ocupar espaço próprio. A estratégia baseada no desenvolvimento e na implantação de tecnologia de informação veio a constituir uma nova etapa da polarização entre as accounting firms e as denominadas firmas de consultoria em estratégia, tão bem representadas pela Mckinsey.

Também merece evidência no período a movimentação incisiva das accounting firms - das quais a Arthur Andersen fazia parte - no intuito de ocupar de maneira mais efetiva o crescente mercado de consultorias. Além do exemplo da criação da Andersen Consulting, ocorreu uma série de fusões entre grandes representantes do setor, visando a um ganho de escala e maior atuação no mercado de consultorias.

A criação das empresas KPMG, Deloitte Touche e Ernst \& Young no final dos anos de 1980, conjuntamente com a presença da Price Waterhouse, Arthur Andersen e Coopers \& Lybrand, viria a compor as denominadas Big Six Accounting Firms. Tal formação constitui importante polo de influência das formas de atuação e configuração do setor de consultorias nos anos de 1990.

Os anos de 1990

Se nos anos de 1980 uma série de posicionamentos e eventos deram suporte a novos espaços para a atuação das consultorias, na década seguinte o setor ganha em destaque e importância nos meios gerenciais e empresariais, destacando-se por suas taxas de crescimento na receita e no porte das empresas, bem como pela exposição na mídia. As receitas passaram de 22 bilhões em 1990 para mais de cem bilhões dez anos depois; além disso, entre as dez maiores empresas, é comum encontrarmos um contingente de empregados que supera o de 50 mil consultores e a receita de cinco bilhões de dólares. Vale lembrar que a Andersen, que nasceu como a maior empresa de consul- 
toria do mundo, em 1989 contava com 21.600 empregados e um faturamento de 1,6 bilhões.

Um primeiro componente que traz contribuições para o entendimento da dinâmica do período é a questão dos processos de reengenharia presentes a partir do início dos anos de 1990. As mudanças associadas aos redesenhos organizacionais, a partir da Core Business, contribuíram para ampliar o espaço das consultorias nos meios gerenciais e empresariais.

Isso não ocorreu apenas em relação ao aumento das possibilidades de atuação, mas, principalmente, em função de características intrínsecas e das consequências da implantação da reengenharia. $\mathrm{O}$ processo de construção e divulgação apresentava propriedades que contemplavam aspectos da dinâmica do setor de consultoria no período. Dentre eles, podem-se destacar as questões relativas às formas de interação entre empresas de consultoria, imprensa de negócios e setores acadêmicos, estes últimos representados sobretudo pelas business schools.

Entretanto, esse crescimento vem acompanhado de uma série de questionamentos relacionados com o cenário no qual essas organizações estão inseridas. De um lado, observa-se sua inserção no crescente mercado de venda de pacotes gerenciais e de novidades organizacionais, em especial sua ligação com a imprensa de negócios e as business schools, proporcionando um interrelacionamento que fortalece o crescimento e dá maior visibilidade ao setor e gerando ainda um flanco de ataque por intermédio das críticas aos chamados modismos gerenciais (Mickletwait e Wooldridge, 1996). De outro lado, há o mistério associado ao mundo das consultorias, quase sempre vinculados aos escassos dados disponíveis e às suas formas de atuação, que recorrem ao sigilo, em diversas ocasiōes, como uma importante alavanca de criação de confiança entre cliente e consultor (O’Shea e Madigan, 1997).

Ao se delimitar esse pano de fundo, cuja diversidade de atores, instituições e organizações tendem a aparentar um complexo cenário de bricolagem, também é possível destacar a relação entre o crescimento do espaço de consultoria e os processos de mudança organizacional pelos quais passam as empresas no decorrer do período. A partir dos anos de 1980, a multiplicação da difusão de "novas formas de gerenciamento" ganha impulso, primeiramente, com a tentativa das organizações ocidentais de acompanharem e recontextualizarem as formas de gestão japonesa; e, no início da década de 1990, com as reestruturações organizacionais, sendo emblemático o exemplo das ideias vinculadas ao processo de reengenharia - segundo Pascale (1990), nos anos de 1980 há um forte incremento na velocidade de surgi- 
mento e na difusão de novas formas de gestão empresarial. Ganham destaque também, no período, os processos de fusões empresariais e de privatização, em especial, quando se analisa o resultado para o tecido organizacional brasileiro com a privatização de setores importantes da base industrial nacional como o siderúrgico, as telecomunicações e o elétrico, bem como o crescente processo de fusões e aquisições no decorrer da década de 1990.

Ganha destaque a perspectiva contida na expressão "um homem, uma ideia, uma nova consultoria", desenvolvida na discussão acerca de modismos e gurus gerenciais. Com a difusão do processo de redesenho organizacional, James Champy e Michael Hammer, considerados os pais da reengenharia, são guindados ao primeiro time de gurus gerenciais internacionais. Suas ideias foram primeiramente expostas no artigo de Michael Hammer, "Reengineering work: don't automate, obliterate" (1990, pp. 104-112), e, posteriormente, em 1993, no livro Reenginerring the corporation (Hammer e Champy, 1993), que alcançou a marca de 17 milhões de exemplares vendidos em todo o mundo, ou seja, a reengenharia tornou-se uma das mais influentes formas de gestão e, simultaneamente, o modismo empresarial das últimas décadas.

Para compreender a relação entre gurus/modismos gerenciais e a dinâmica de consultoria é preciso lembrar que, durante a década de 1980, são diversos os exemplos de agentes que se revezam na formulação e na venda de "pacotes gerenciais", tais como Crosby (1980), Porter (1980) e Kanter (1983). Assim, a difusão da reengenharia é oriunda dessa forma de atuação no mercado, fornecendo respaldo a possíveis candidatos a esse tipo de consultoria.

A divulgação centrada em artigos, revistas e especialmente num livro, que deveria se tornar carro-chefe das ideias, cujo autor seria transformado posteriormente em guru, possuía elementos que vinham ao encontro da crescente atuação de professores, principalmente das business schools, em consultorias especializadas e de pequeno porte, por exemplo. Para essas empresas o sucesso do formato da reengenharia fornecia a possibilidade de alcançar o restrito mundo das consultorias, representado pelas accounting firms, e das empresas de estratégia.

Com as mudanças organizacionais nas empresas, uma das formulações mais centrais das ideias de reengenharia, o Downsizing, também contribuiu para a caracterização e a difusão das consultorias. Representado pelo achatamento da pirâmide de posições, cortes de funções - em alguns casos, de departamentos inteiros - e processos de terceirização, um contingente de 
gerentes deslocado dos antigos empregos buscou nas consultorias uma maneira de reconversão, seja prestando serviços às antigas empresas, seja formando novas empresas que fornecessem orientação sobre assuntos específicos antes desenvolvidos no trabalho.

As construçôes e as representações das empresas, vinculadas à necessidade de uma pirâmide gerencial, também tinham como consequência o aumento na competição interna por cargos gerenciais, o que, muitas vezes, levava os ocupantes de tais posiçôes a buscar, com base nas ideias de consultores, gurus e livros, novas formas de gestão que possibilitassem valiosos pontos na disputa interna das empresas.

Para sintetizar e compreender as transformações e os posicionamentos dos agentes no espaço de consultoria internacional, recorro a duas questões principais. A primeira remete às dimensões que as empresas líderes do setor foram adquirindo principalmente a partir do final dos anos de 1980. Por exemplo, a Andersen Consulting passou de 21.660 funcionários, em 1990, para 45 mil, em 1996. Seu faturamento também apresenta um crescimento significativo, aproximando-se da cifra de 5,3 bilhōes em 1996 contra 1,6 de seis anos antes.

Para se compreender tal crescimento, é preciso lembrar da movimentação das accounting firms no sentido de ocupar o mercado de consultoria por meio da criação da Andersen Consulting ou por fusões de empresas como a KPMG. Independentemente da forma, as big six - KPMG, Deloitte Touche, Ernst \& Young, Price Waterhouse, Arthur Andersen e Coopers \& Lybrand - tornaram-se o polo dominante no mercado mundial de consultoria, influenciando tanto em razão do ganho de escala, proporcionado pelo porte das empresas, como pela abrangência de sua área de atuação. Por exemplo, em 1996, a Price contava com quatrocentos escritórios em 118 países e a Andersen com 152 escritórios em 46 países.

Outro polo tradicional do período de formação das empresas de consultoria é o setor das empresas especializadas em Estratégia Organizacional, tendo como ícones a Mckinsey, a Booz-Allen e a Hamilton. O caso da Mckinsey é exemplar, tendo em vista o faturamento de 2,9 bilhões e o fato de ter aumentado o contingente de consultores de 600 , no início da década de 1980, para 3.900, em 1996, atuando em 32 países.

Também é relevante o crescimento das empresas de consultoria no campo da tecnologia de informação. Destacam-se aí a liderança da Andersen Consulting e a movimentação de gigantes do ramo de informática por meio de diversificação dos negócios, como a IBM. Essas empresas buscavam ocu- 
par um espaço no mercado de consultorias, vendendo soluçôes que aliassem os processos de mudanças e formulações estratégicas com o suporte da tecnologia de informação.

Ademais, temos o crescimento do espaço ocupado pelas empresas que tinham sua origem e principal área de atuação na transformação de teorias e ideias desenvolvidas nos meios acadêmicos em pacotes gerenciais. Mais especificamente pelo posicionamento da BCG Consulting. Desde os anos de 1960, esta firma oferecia ferramentas baseadas em conceitos acerca do mundo empresarial que pudessem ser facilmente assimilados e manipulados, sendo emblemática a sua matrix de portifólio, em muitos casos, confundida com a própria empresa. Buscava-se classificar as empresas em quatro grupos de acordo com sua capacidade de gerar receitas e ocupar parcelas de mercado. A identificação do grupo em que a empresa se classificava fornecia uma expectativa de retorno do capital investido e informava os riscos associados a este investimento. A funcionalidade e a simplicidade do esquema que cobria os mais diversos ramos industriais serviram de base para o sucesso e a difusão do mesmo, configurando-se, praticamente, como um blue book, no qual os executivos poderiam buscar de forma automática auxílio para a tomada de decisões.

A importância da posição da BCG em relação às outras consultorias serve de indicativo do crescente espaço que essa forma de atuação ganhou no mercado de consultoria e também das mudanças por que passavam essas empresas, que se caracterizavam pelo pequeno porte, contando normalmente com no máximo uma centena de empregados, no caso de firmas de tamanho considerável; em contraposição, a BCG, em 1996, era composta por 1.500 funcionários.

Além da maior visibilidade e das novas de áreas de atuação, o crescimento das consultorias na primeira de década de 1990 também trouxe questionamentos sobre a eficácia e as formas de atuação dos consultores, gerando debates acerca de modismos e gurus gerenciais. Começam a aparecer de forma sistemática críticas à sucessão de "fórmulas salvadoras de empresas" e às condutas éticas dos consultores. O caso da AT\&T, um dos gigantes do setor de telecomunicação mundial, é emblemático. A empresa a partir dos anos 1980 tornou-se uma das principais clientes das consultorias, tendo gasto só na primeira metade dos anos de 1980 mais de meio bilhão de dólares em tais serviços. Entretanto, apesar de armada de um exército de consultores e dos mais variados tipos de fórmulas de sucesso, a companhia apresentou um desempenho que passava longe do previsto. No caso da compra da NCR, 
por exemplo, por um valor bem acima daquele de mercado. John Walter, ao tomar posse como novo presidente, em novembro de 1996, decidiu afastar todos os consultores e declarar que não eram mais bem-vindos na empresa (O’Shea e Madigan, 1997).

$\mathrm{Na}$ imprensa de negócios, que em muito contribuiu e beneficiou-se dos best-sellers sobre novas formas de gestão, também começaram a aparecer artigos e livros que questionavam os consultores e os modismos gerenciais. Como exemplo de artigos, temos: "In search of suckers" (Fortune, 1996) e "The rise of guru scepticism" (Management Today, 1996); e de livros: The witch doctors: making sense of the management gurus (Micklethwait e Wooldridge, 1996); Management redeemed: debunking the fads that undermine corporate performance (Hilmer e Donaldson, 1996); Dangerous company: The consulting powerhouses and the businesses they save and ruin (O'Shea $\mathrm{e}$ Madigan, 1997); e Fad surfing in the boardroom: reclaiming the courage to manage in the age of instant answers (Shapiro, 1997). Nas listas de best-sellers também figuravam dois livros de desenhos em quadrinhos de Scott Adams, The Dilbert principle e Dogbert's top secret management handbook, que, entre outros assuntos sobre o cotidiano nas grandes empresas, satirizavam as práticas dos consultores.

Diante das críticas, dois movimentos marcaram essa área no final dos anos de 1990. O primeiro buscava dar conta dos questionamentos acerca da ética e da quase inexistência de barreiras de entrada no setor, que facultava, conforme esse entendimento, a qualquer pessoa apresentar-se e atuar como consultor apenas imprimindo cartôes de visita e, portanto, ocasionando situações desastrosas. O Institute of Management Consulting - IMC, principal associação profissional dos consultores norte-americanos, começou a implementar programas de certificação para o exercício da atividade. Para a obtenção do certificado era necessário ser aprovado em exame no qual o candidato deveria demonstrar domínio e experiência comprovada na condução e na implementação dos assuntos nos quais pretendia trabalhar.

As críticas aliadas a um acirramento na concorrência também começaram a influir na forma de atuação dos consultores. Não era mais permitido, como acontecia na década de 1980, vender análises e ideias de mudanças, exceto, conjuntamente com o diagnóstico e pacotes gerenciais, um movimento na direção de implementar as soluções propostas.

Apesar dos questionamentos, o setor manteve um crescimento que ganhava destaque nos meios empresariais na segunda metade dos anos de 1990, fechando a década com crescimento de aproximadamente 354\%, 
faturamento $150 \%$ maior que no ano de 1995, além de apresentar abrangência mundial.

Para fechar a cronologia do período e fornecer elementos que auxiliem no entendimento da dinâmica do setor, é possível destacar alguns aspectos que ajudam a entender as transformaçôes ocorridas no final da década de 1990. Uma primeira verificação possível é o surgimento da Accenture Consulting como maior empresa em faturamento do setor. A nova firma foi resultado de uma disputa jurídica entre a Arthur Andersen e a Andersen Consulting. Na consideração do embate pode-se destacar dois aspectos centrais: o primeiro relativo ao crescimento do faturamento do setor de consultoria em relação às tradicionais áreas de atuação das Accounting Firms, exemplificado pelo fato de que, em 1997, pela primeira vez o setor de management consulting tinha receita maior que a de auditoria e impostos. A disputa era balizada na idade, na formação profissional e na forma de atuação dos envolvidos. Do lado mais tradicional, havia auditores, advogados e pessoas ligadas a aspectos de contabilidade, com uma relação fundamentada na longevidade, na continuidade e no sigilo das transações com os clientes. Em contrapartida, havia um exército de jovens recém-saídos das business schools e centros de tecnologia, armados de MBAs e habilidades em tecnologias de Informação e com um relacionamento baseado na venda de ferramentas e pacotes gestão.

A questão também passava por aspectos jurídicos, uma vez que começavam ganhar evidência as discussões acerca da legalidade de operações de avaliação e também da implantação das mudanças em empresas em processo de fusão e pela mesma consultoria, sendo referência o fato da Deloitte \& Touche optar pela atuação, no primeiro segmento, em atividades que determinaram sua origem, como uma empresa de accounting, e por vender o segundo segmento à Cap Gemini.

Cabe também destacar a continuidade no processo de fusão entre grandes empresas com a junção da Pricewaterhouse e Coopers \& Lybrand. A nova empresa nasceu como a segunda maior em consultoria do mundo, com um faturamento que superava os nove bilhões de dólares e representava concentração ainda maior tanto nas accountings firms, com atuação mundial, como nos setores das consultorias oriundas destas, que agora formavam não mais as big six, mas sim as bigfive: Pricewaterhousecoopers, Arthur Andersen, Ernst \& Young, KPMG e Deloitte Consulting.

Por outro lado, firmas especializadas em estratégia, focadas na difusão de pacotes gerenciais e de IT, ofereciam também serviços que pudessem 
contemplar "soluções completas" tanto em suas especialidades como nas desenvolvidas pelos concorrentes. Isso se dava por meio do desenvolvimento de setores dedicados e/ou alianças entre empresas. Como exemplo, temse a CSC Consulting, que foi formada a partir de sua fusão com a Index, e aliava o crescimento originário na difusão e na implementação dos processos de reengenharia - à frente dos quais um dos fundadores da empresa, James Champy, era uma das principais referências mundiais - e a tecnologia de informação desenvolvida pela Index. Como resultado da fusão, a empresa tornou-se a quinta maior consultoria do mundo.

\section{Novos formatos das empresas, crescimento das consultorias e mudanças dos conteúdos gerenciais}

O crescimento do mercado, aliado aos processos de fusão e alianças entre empresas, e a necessidade de atuação em escala mundial acentuaram ainda mais a tendência, presente no decorrer dos anos de 1990, de aumento significativo do tamanho e do valor das receitas das consultorias. As empresas dessa área despontam como um dos elementos de difusão e introdução de novos arranjos organizacionais, influenciando e, em muitos casos, direcionando a agenda dos possíveis formatos organizacionais. A relação entre as firmas de consultoria e as demais organizaçóes é um importante elemento para o entendimento da dinâmica organizacional do período.

Analisando essa dinâmica numa primeira abordagem, é possível estabelecer conexões que possibilitem o entendimento do crescimento do setor. Os processos de reorganização associados às novas configurações do controle das empresas, representados emblematicamente pelas fusões, aquisições e, em especial, no caso brasileiro, pela privatização, abrem um grande espaço de atuação. Utilizam-se, como suporte para a discussão da dinâmica do espaço de consultoria e para a análise dos embates entre gerentes e consultores, dados e interpretaçóes provenientes da cartografia inicial do espaço de consultoria brasileiro (Donadone, 2003).

Para auxiliar no entendimento da relação entre consultores e empresas é preciso centrar-se nas funções das consultorias. Como ponto de partida recorro às formulações teóricas de Coget (1999), segundo as quais a atuação dos consultores concentrava-se em três categorias. A primeira, ligada ao uso dos consultores na arbitragem de disputas internas e externas às empresas, fornecendo legitimidade às ações. A segunda, relacionada com a capacidade dos consultores de produzir e difundir conceitos acerca do mundo 
empresarial. Como última característica, aparece sua atuação na implementação de mudanças organizacionais.

Quanto à questão da arbitragem externa, os embates entre os novos "donos" das empresas constituem um amplo campo para a utilização das consultorias como meio legítimo de análise do desempenho financeiro. Como exemplo, tem-se a forma de estruturação da venda de empresas estatais, na qual duas consultorias avaliam as firmas, apontam seus problemas e sugerem compradores. Nas disputas internas, torna-se comum o uso das consultorias como uma arma na disputa pela validação do desempenho de determinada unidade ou departamento perante os demais setores da empresa, principalmente com a crescente focalização dos core process e, em consequência, a venda ou desativação das áreas pouco rentáveis.

A questão da utilização do ideário oriundo das consultorias bem como dos consultores na implementação de mudanças organizacionais vem no bojo dessas reestruturações. Os gerentes buscam aumentar o desempenho das suas unidades como uma tentativa de alcançar o resultado econômico esperado. Com esse objetivo, procuram soluções que possam auxiliá-los. Cabe ressaltar que os processos de busca de legitimidade para as ações e a implementação das mudanças organizacionais estão intimamente relacionados e que a justificativa pela escolha, em muitos casos, dá suporte à sua implementação.

QUADRO 1

As formas de atuação dos consultores nos processo de mudanças organizacionais

\begin{tabular}{ll}
\hline ARBITRAGEM EXTERNA & $\begin{array}{l}\text { Avaliar as empresas, apontar seus problemas e sugerir compradores nos processos } \\
\text { de fusōes e privatizaçōes. } \\
\text { Validar o desempenho de determinada unidade ou departamento. }\end{array}$ \\
\hline DifUNDIR/GERAR & $\begin{array}{l}\text { Crescente literatura/gurus sobre como gerenciar as empresas. } \\
\text { CONCEITOS GERENCIAIS }\end{array}$ \\
\hline Busca de legitimidade e referência perante as mudanças na empresas. \\
\hline
\end{tabular}

As transformações que estão em curso nas organizaçóes têm fundamentos sutis que ultrapassam as explicações fornecidas acerca dos processos de mudança mais comumente difundidos na análise organizacional. Assim, recorro a duas formulações teóricas na tentativa de aprofundar a análise do crescimento do espaço de atuação das consultorias. 
Primeiramente, remeto aos conceitos de Orlean referentes à realização do poder da lógica financeira. Suas formulações enfatizam que o ponto central desta, a liquidez dos investimentos, está baseado num sistema de opinióes amparado por um mecanismo cognitivo, ou seja, a expectativa de lucro sobre determinados investimentos depende de uma série de avaliações que se autorreferenciam e que têm sentido somente a partir desse ponto de vista.

Tal construção teórica traz contribuições importantes a este trabalho, no que diz respeito à necessidade da transparência das codificaçôes das informaçôes econômicas como instrumentos essenciais de poder e influência da lógica financeira na empresa, ou seja, a capacidade de avaliar o desempenho empresarial e de arbitrar. Nesse sentido, vale lembrar que a formação e o desenvolvimento do setor de consultorias em muito fundamentaram-se nos relatórios sobre a saúde financeira das companhias, como nos emblemáticos survey's bank. A questão também remete aos conteúdos teóricos formulados por Fligstein (1990) sobre o processo de construção da lógica financeira, ou seja, as firmas recorriam à análise econômica como forma de acompanhar e avaliar o desempenho das aquisiçóes em setores com os quais tinham pouca familiaridade. Característica também presente e intrínseca aos investidores institucionais.

Como outro suporte para a análise aqui desenvolvida remeto aos trabalhos de Douglas, em especial suas formulaçóes acerca dos sistemas de classificação cultural por meio dos quais os agentes dão sentido e formato às suas ações.

Como verifica Useem (1993), com o crescimento da influência dos investidores institucionais há uma mudança nos conteúdos atribuídos aos gerentes dos diversos níveis da empresa. $\mathrm{O}$ formato, que baseava a atuação do gerente no cumprimento rigoroso das tarefas e considerava a carreira como uma série de posiçōes a serem ocupadas nos diversos níveis hierárquicos, começa a ser questionado. A forma de poder resultante da hierarquização burocrática começa a sofrer sérios danos. Com a demissão de parcela considerável da gerência média e a necessidade de pensar a empresa em termos econômicos e a curto prazo, começa a ruir o esquema de distribuição de poder formado ao longo das últimas décadas de revolução gerencial.

$\mathrm{Na}$ literatura do período aparece uma série de títulos que chamam a atenção para o processo de perda de poder dos gerentes e da transformação do seu relacionamento com a empresa em bases somente financeiras (por exemplo, "A corrosão do caráter, consequências pessoais do trabalho no novo capitalismo"; Le manager jetable; L'entreprise barbare). Ou ainda na análise de pu- 
blicações sobre trabalhos gerenciais divulgadas pela revista Exame, no decorrer da década, por exemplo, quanto à relação centrada em aspectos financeiros com empresas: "O executivo é o próprio negócio"; "Seja seu próprio Head Hunter"; "Negociar em causa própria não é feio". Já quanto às representaçōes das estruturas organizacionais: "Não se fazem mais pirâmides como antes"; "A hierarquia treme"; "Somem cadeiras no Olimpo". Ou como síntese das duas temáticas: "Prepare-se, vem aí o executivo ocasional".

Ao considerarmos essa questão com base nas formulaçôes de Douglas (1996), é possível tecer considerações que nos ajudam a entender as mudanças. Parece que se pode identificar um processo de guerra cultural onde a visão financeira da empresa se encontra situada no quadrante do individualismo ativo, no qual seus representantes buscam a maximização dos seus investimentos no curto prazo e dessa maneira desenham o controle das organizações.

No outro polo encontram-se os gerentes com suas expectativas desenvolvidas de acordo com um esquema cognitivo formado na burocracia, ou seja, por uma forte hierarquização. $\mathrm{O}$ formato do embate ganha importância para o esquema explicativo deste trabalho, uma vez que, nas entrevistas com consultores, foi consenso a apresentação do mundo gerencial como burocrata ou como aquele "que criava barriga na mesma empresa". Cabe ressaltar que os processos de hierarquização e classificação próprios da estruturação do campo desenvolviam-se não apenas em embates discursivos, mas também eram internalizados nas organizações, sendo representativo o formato matricial de trabalho das grandes consultorias, ou os "projetos" das consultorias acadêmicas, diante da sempre mencionada pirâmide organizacional das empresas.

Outra questão que merece destaque é a forma de ascensão na carreira de consultor nas grandes empresas. Nesse sentido são centrais as ideias associadas ao UP or Out, ou seja, a combinação de um forte afunilamento nas possibilidades de promoção com uma prática de demissão ou quase exclusão voluntária dos que ultrapassa um determinado período de vínculo com as empresas, normalmente cerca de três a cinco anos. Tal mecanismo e as formas de socialização ligadas a ele produziam um repertório de entendimento sobre os possíveis arranjos organizacionais que vinha ao encontro das formas de promoção e carreira das empresas industriais, normalmente estruturadas a partir de diversos níveis gerenciais baseados em um modelo de distribuição de poder fortemente hierarquizado. $\mathrm{O}$ interessante é que a polarização se dava, ainda que com contornos e grau de sofisticação de ar- 
gumentos diferentes, também entre os consultores individuais como, por exemplo, em construções do tipo: "agora não dependo de ninguém para subir" ou "as empresa deveriam dar trabalho, não emprego às pessoas" (Donadone, 2003).

O formato dos embates entre consultores e gerentes era direcionado pelo posicionamento nos respectivos campos, ou seja, houve uma mitigação na diferenciação entre consultores e gerentes em posições homólogas. Nesse sentido é emblemática a relação entre as formulações dos consultores da Mckinsey e seus clientes, em número considerável, diretores de grandes empresas e egressos da mesma. Por outro lado, no processo de violência simbólica, tal como discutido por Bourdieu (2000), os embates passaram praticamente a não ser mais mencionados, naturalizando-se a posição dominante, indicada pelo fato de gerentes atribuírem à atuação dos consultores o modelo de conduta a ser seguido perante um "mundo que privilegia o curto prazo e a capacidade de se vender todo dia".

Por fim, o último tópico traz formulações que são fonte de novas pesquisas em processo de desenvolvimento, as quais contemplam os conteúdos gerenciais surgidos a partir das novas configuraçóes nas empresas e as formas de inter-relacionamento entre consultores e gerentes.

\section{GRÁFICO 1}

O Mercado Mundial de Consultorias

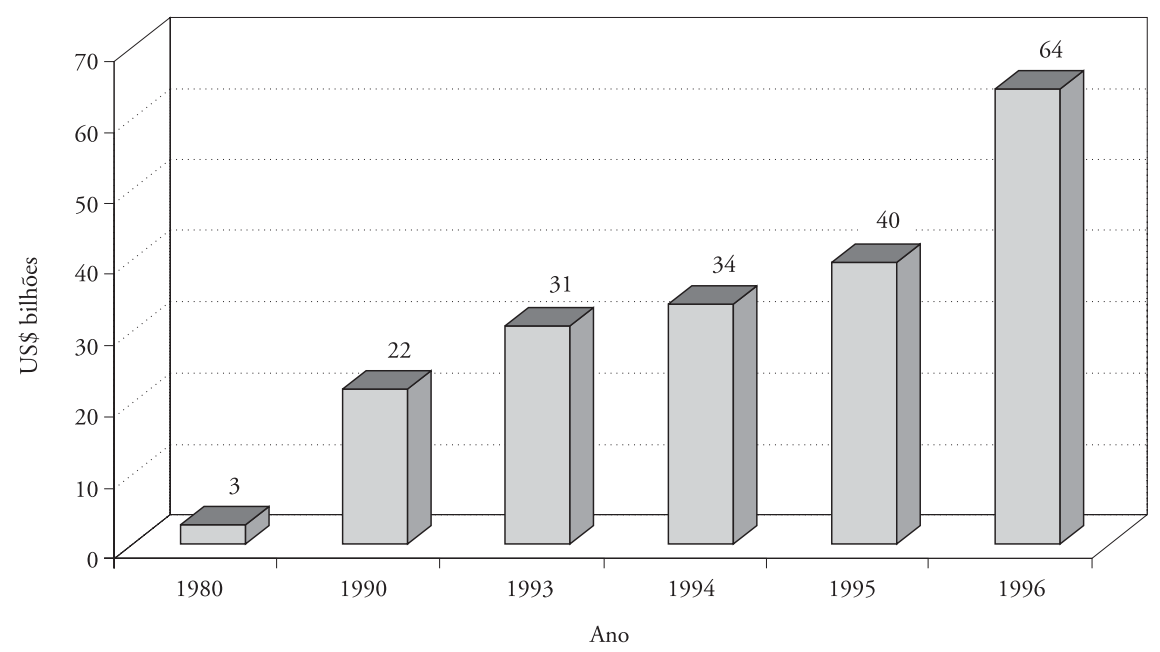

Fonte: Consultants News, The Economist, Journal of Managemente Consulting. Ver Barcus e Wilkinson (1995). 
GRÁFICO 2

O Mercado Mundial de Consultorias nos anos de 1990

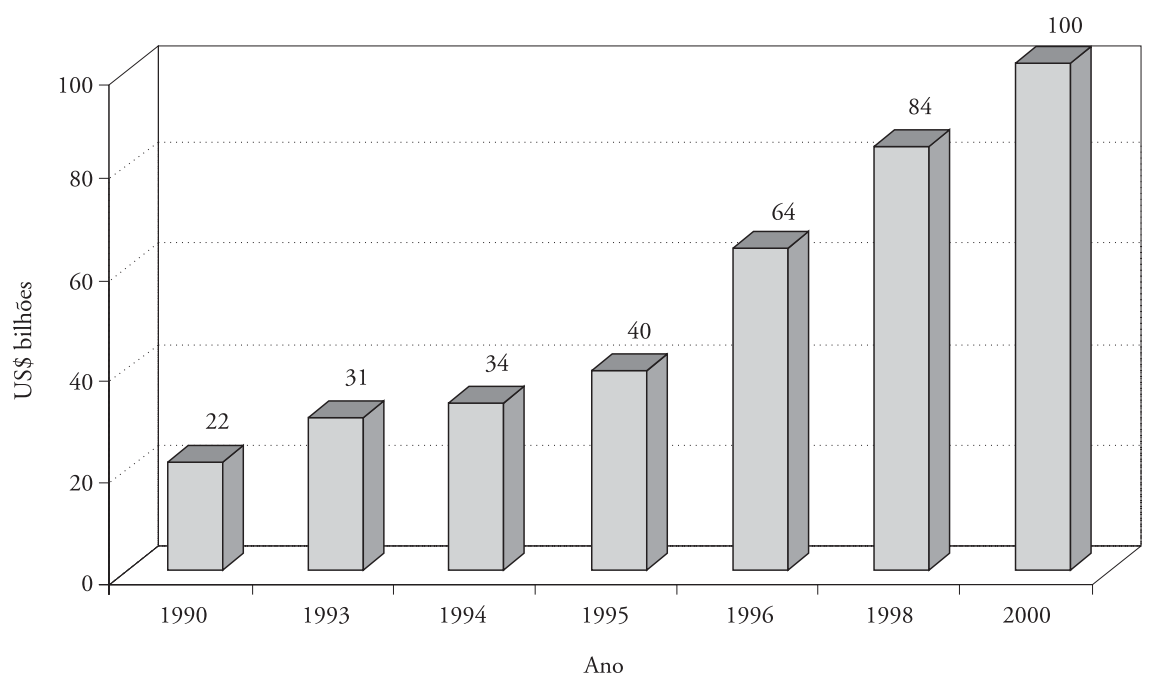

Fonte: Consultants News, The Economist, Journal of Managemente Consulting. Ver Barcus e Wilkinson (1995).

\section{Referências Bibliográficas}

Adams, Scott. (1997), Dogbert's top secret management handbook. Nova York, Harper Paperbacks.

. (1997), The Dilbert principle: a cubicle's-eye veiw of bosses, meetings, management fads and other workplace afflictions. Nova York, Harper Paperbacks.

Barcus, Saw W. \& Wilkinson, Joseph W. (eds.). (1995), Handbook of management consulting services. Nova York, McGraw-Hill.

Bourdieu, Pierre. (2000), Les structures sociales de l'économie. Paris, Éditions du Seuil. Chandler Jr., A. D. (1990), “The emergence of managerial capitalism”. In: Zukin, A. e Dimaggio, P. J. Structures of capital: the social organization of the economy. Cambridge, Cambridge University Press.

Coget, Xavier. (1999), Les cabinetes de conseil en management: origines et funciones. Paris, tese de doutorado, École des Hautes études en Ciencias Sociales.

Comin, A. (1996), "O crescimento das fusões e aquisições no Brasil e no mundo: uma avaliação das tendências recentes". LEP, Campinas, 3: 63-87, dez.

Crosby, Philip. (1980), Quality is free. Nova York, McGraw-Hill.

Donadone, J. C. (2003), Os hunos já chegaram: dinâmica organizacional, difusão de conceitos gerenciais e a atuação das consultorias. São Paulo, tese de doutorado, Escola Politécnica da Universidade de São Paulo. 
Douglas, Mary. (1996), Thought styles: critical essays on good taste. Londres, Sage.

Durieux, Albert \& Jourdain, Stéphène. (2000), L'entreprise barbare, Paris, Albin Michel.

Fligstein, N. \& Markowitz, L. (1993), "The finance conception of the corporation and the causes of de finance reorganization of large corporation, 1979-1988". In: WiLSON, W. J. (ed.), Sociology and social policy. Beverly Hills, Sage.

HAMmer, Michael. (1990), "Reengineering work: don't automate, obliterate". Harvard Business Review, pp.104-112, july-august.

HAMmer, Michael \& CHAMpy, James. (1993), Reengineering the corporation: a manifesto for business revolution. Londres, Harpercollins Publishers.

Henry, Odile. (1992), "Entre savoir et povoir". Actes de la Recherche en Sciences Sociales, Paris, 95: 37-54, dez.

Hewes Jr., James E. (1996), "From root to McNamara: army organization and administration". Business and Economic History, 1 (25), fall.

Hilmer, Frederick G. \& Donalds, Lex. (1996), Management redeemed. Nova York, Free Press.

Hoover, Herbert. (1996), "Manuscript for the Encyclopedia Britannica Book of the Year". Business and Economic History, 1 (25), fall.

Kanter, Rosabeth. (1983), The change masters. Nova York, Simon \&. Schuster.

KIPING, Mathias. (1996), "The U.S. influence on the evolution of management consultancies in Britain, France and Germany since 1945”. Business e Economic History, 1 (25), fall.

Mckenna, Christopher D. (1995), "The origins of modern management consulting". Business and Economic History, 1 (24), fall.

. (1996), "Agents of adhocracy: management consultants and the reorganization of the executive branch, 1947-1949". Business and Economic History, 1 (25), fall.

Mello JR., Luiz R. (2000), "Privatização e governança empresarial no Brasil”. In: Pinheiro, Armando Castelar \& FuKasaku, Kiichiro (eds.), A privatização no Brasil: o caso dos serviços de utilidade pública. Rio de Janeiro, BNDES.

Micklethwait, John. \& Wooldridge, Adrian. (1996), The witch doctors: making sense of the management gurus. Nova York, Times Books.

OrléAn, André. (1999), Le pouvoir de la finance. Paris, Odile Jacob.

O’Shea, James E. \& Madigan, Charles. (1997), Dangerous company. "The consulting powerhouse and the businesses they save and ruin". Nova York, Times Business.

Pascale, Richard Tanner. (1990), Managing on the edge. Nova York, Simon and Schuster.

Pinheiro, Armando Castelar. (1999), "Privatização no Brasil: Por quê? Até onde? Até quando?”. In: Giambiagi, Fábio e Moreira, Maurício Mesquita (orgs.). A economia brasileira nos anos 90. Rio de Janeiro, BNDES. 
Porter, Michael E. (1980), Competitive strategy. Nova York, Free Press.

SENNETT, Richard. (1999), A corrosão do caráter: consequências pessoais do trabalho no novo capitalismo. Rio de Janeiro, Record.

SHAPIRO, Eillen. (1997), Fad surfing in the boardroom: managing in the age of instant answers. Nova York, Basic Books.

Siffert Filho, Nelson \& Souza e Silva, Carla. (1999), "As grandes empresas nos anos 90: respostas estratégicas a um cenário de mudanças". In: GiambiaGi, Fábio e Moreira, Maurício Mesquita (orgs.). A economia brasileira nos anos 90. Rio de Janeiro, BNDES.

UsEem, Michael. (1999), Investor capitalism: how money managers are changing the face of corporate America. Nova York, Basic Books.

. (1993), Executive defense. Shareholder power and corporate reorganization.

Cambridge, Massachusetts, Harvard University Press.

Villette, Michel. (1996), "Le manager jetable. La découverte".

Wasburn, Steward A. (1996), "Challenge and renewal: a historical view of the profession”. Journal of management consulting, pp. 47-53, nov.

WiLKInSON, Joseph W. (1995), "What is management consulting?". In: $\&$

Baecus, Saw. W. (eds.). Handbook of Management Consulting Services. Nova York: Ed. McGraw-Hill.

Zilbovicius, Mauro. (1999). Modelos de produção, produção de modelos: gênese, lógica e difusão do modelo japonês. São Paulo, Annablume/Fapesp. 


\section{Resumo}

Consultoria internacional em expansão e formas emergentes de globalização das trocas e contenciosos gerenciais

Proponho estudar diretamente as articulações sociais que produzem a internacionalização e suas formas de naturalização dos conteúdos gerenciais. Para tanto, este estudo pretende contribuir para o entendimento do processo de crescimento do mercado brasileiro de consultorias, suas formas de atuação e o relacionamento com as demais organizaçôes, procurando identificar suas características bem como as principais mudanças nas últimas décadas.

Palavras-chave: Consultoria; Internacionalização; Recontextualização; Consultores e conteúdos gerenciais.

\section{Abstract}

International consultancy in expansion and emerging forms of the globalization of managerial exchange and litigation

I propose a direct study of the social articulations that produce this internationalization of managerial content and the forms of naturalizing it. In order to do this, the study will contribute to an understanding of the growth process in the Brazilian consultancy market, its ways of operating and relationship with all other organizations, thus striving to identify its characteristics and key changes over the decades. Keywords: Consultancy; Internationalization; Re-contextualization; Consultants and managerial content.

Texto recebido em $17 /$ $1 / 2008$ e aprovado em 9/3/2010.

Julio César Donadone é professor associado e coordenador do Núcleo de Sociologia Econômica e das Finanças (Nesefi)da Universidade Federal de São Carlos. E-mail: <donadojc @uol.com.br>. 